\title{
Sodium Chloride and Water Transport in the Descending Limb of Henle
}

\author{
JUHA P. KoKKo \\ From the Department of Internal Medicine, The University of Texas (South- \\ western) Medical School, Dallas, Texas 75235
}

A в S T R A C T The unique membrane characteristics of the thin descending limb of Henle (DLH) play an integral part in the operation of the countercurrent system. We examined these properties in vitro by perfusing isolated thin descending limbs of rabbits. Active transport of $\mathrm{NaCl}$ was ruled out by failure to demonstrate either net transport or transmembrane potential difference when perfusing with isosmolal ultrafiltrate of the same rabbit serum as the bath. Transmembrane potential was zero, and net fluid transport was $-0.07 \pm 0.06$

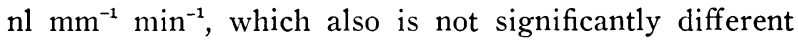
from zero. Passive permeability coefficient for $\mathrm{Na}\left(\mathrm{P}_{\mathrm{Na}}\right)$ was determined from the disappearance rate of ${ }^{22} \mathrm{Na}$ from isosmolal perfusion solution. $\mathrm{P}_{\mathrm{Na}}$ was surprisingly low, $1.61 \pm 0.27 \times 10^{-5} \mathrm{~cm} \mathrm{sec}^{-1}$, a figure which is significantly less than $P_{x a}$ in the proximal convoluted tubule (PCT). Reflection coefficient for $\mathrm{NaCl}(\sigma \mathrm{NaCl})$ was measured by perfusing the tubule with $\mathrm{Na}$-free raffinose solution in a bath of rabbit serum to which sufficient $\mathrm{NaCl}$ was added to obtain conditions of zero net fluid movement. The measured $\sigma \mathrm{NaCl}$ of $0.96 \pm 0.01$ is significantly greater than $\sigma \mathrm{NaCl}$ in the PCT. Water permeability to osmotic gradients $\left(\mathrm{L}_{\mathrm{p}}\right)$ was determined by perfusing with ultrafiltrate of rabbit serum in a bath made hyperosmotic by addition of either $100 \mathrm{mOsm}$ raffinose or $\mathrm{NaCl}$. $\mathrm{L}_{\mathrm{p}}$ with raffinose was $1.71 \pm 0.15$ $\times 10^{-4} \mathrm{ml} \mathrm{cm}^{-2} \mathrm{sec}^{-1} \mathrm{~atm}^{-1}$ and with $\mathrm{NaCl} 1.62 \pm 0.05 \times$ $10^{-4} \mathrm{ml} \mathrm{cm}^{-3} \mathrm{sec}^{-1} \mathrm{~atm}^{-1}$, indicating much greater water permeability than in the PCT. In each case the measured increase in osmolality of the collected fluid was primarily due to water efflux without significant influx of solute.

The finding of low permeability to sodium and high

This work was presented in part at the meeting of the American Society of Clinical Investigation, Atlantic City, N. J., 3 May 1970.

Received for publication 7 April 1970 and in revised form 25 May 1970. permeability to water is consonant with the hypotheses that high interstitial concentration of $\mathrm{Na}$ in the medulla generates an effective osmotic pressure which results in concentration of the fluid as it courses through the DLH primarily by abstraction of water without significant net entry of $\mathrm{NaCl}$.

\section{INTRODUCTION}

The tubular fluid in the descending limb of Henle (DLH) becomes progressively more concentrated as it travels from the corticomedullary junction towards the papillary tip. The mechanism by which this takes place is not clear. Two basically different ways may be postulated. First, water may be primarily abstracted without influx of solute. Alternatively, influx of solute may predominate with only minimal efflux of fluid. These two mechanisms demand entirely different membrane characteristics. In the former hypothesis the membrane would be quite permeable to water but relatively impermeable to $\mathrm{NaCl}$, while in the latter hypothesis the membrane would require a high permeability to $\mathrm{NaCl}$.

The relative inaccessibility of the thin, descending loop of Henle to conventional micropuncture techniques has prevented previous quantitative evaluation of its passive permeability properties. The present study was designed to obtain this information by in vitro perfusion of isolated segments of DLH dissected from rabbit kidneys. The results of direct measurements of the hydraulic permeability to water $\left(L_{p}\right)$, passive permeability to $\mathrm{NaCl}\left(\mathrm{P}_{\mathrm{Na}}\right)$, and reflection coefficient of $\mathrm{NaCl}$ $(\sigma \mathrm{NaCl})$ will be presented together with measurements of those membrane characteristics which allow for evaluation of active tranpsort of $\mathrm{NaCl}$. The combination of these properties will be discussed with reference to the mechanism by which the intraluminal fluid of the DLH becomes hyperosmotic.

1838 The Journal of Clinical Investigation Volume 491970 


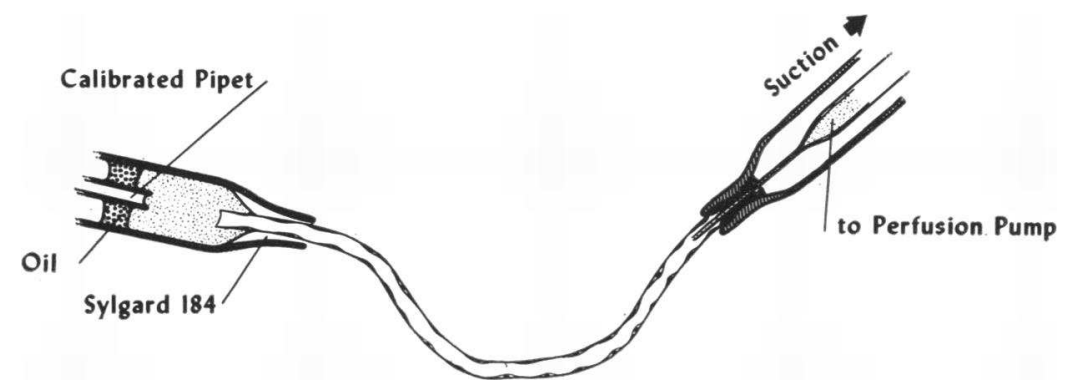

FIGURE 1 Diagrammatic illustration of the method by which thin descending limbs of Henle are perfused in vitro. The holding pipette at the perfusion end has an I.D. of $36-40 \mu$. The perfusion pipette o.D. ranges from 12 to $20 \mu$. The collecting pipette I.D. is $22-24 \mu$. Fluid is periodically sampled from the collecting pipette with a constant bore calibrated pipette. The bathing chamber holds 1.25 cc of fluid.

\section{METHODS}

Isolated segments of thin descending limbs of Henle were perfused by the general techniques described (1) for the PCT of rabbit. Schematic representation of these exper1ments is given in Fig. 1, and actual photographs of perfused loop are shown in Figs. 2 and 3. Female New Zealand white rabbits weighing $1.5-2.5 \mathrm{~kg}$ were used in all experiments. After the rabbit was decapitated by use of a guillotine, the kidney was quickly removed, and cut horizontally in 1- to 2-mm slices, and segments of these slices were transferred into chilled dishes of rabbit serum where the individual loop was dissected free without use of collagenase or other enzymatic agents. Positive identification was obtained by dissecting the loop intact with the pars recta. Most of the nephrons perfused were from the mid-medullary region. After dissection the distal end of the loop was cut with microscissors, followed by removal of the pars recta in a similar manner. The remaining descending thin limb was transferred into a perfusion dish of rabbit serum which was kept at $37^{\circ} \mathrm{C}$ and $\mathrm{pH}$ of 7.4 by continuous bubbling with $5 \% \quad \mathrm{CO}_{2}-95 \% \quad \mathrm{O}_{2}$. The tubule was then picked up by suction into small pipettes and perfused by means of a concentric glass pipette, as illustrated in Fig. 1. Good electrical seal was obtained at the collecting end by placing a small quantity of Sylgard-184 (Dow Corning Corp., Midland, Mich.) at the tissue-glass junction in the collecting pipette (2). Colored mineral oil was placed on top of the collected fluid to minimize evaporation. During each experiment three control periods were obtained at 10 -min intervals. After this the desired experimental manipulation was performed, and three additional 10-min collections were obtained. In this manner, each individual tubule acted as its own control.

Active transport of $\mathrm{NaCl}$ by the thin descending limb was evaluated by measuring ( $a$ ) transmembrane potential and $(b)$ the magnitude of net fluid transport. The transmembrane potential was measured by placing a $\mathrm{Ag}-\mathrm{AgCl}$ electrode into the perfusion pipette containing isomolal ultrafiltrate of the same rabbit serum as that used in the bath. A similar reference electrode was connected to the bath by an agar bridge. The circuit was completed by placing a voltage reference source and a General Radio Company (West Concord, Mass.) Model 1230-A electrometer in the circuit by techniques similar to schematics previously published (3). Any observed voltage was adjusted to zero before perfusion of the individual tubule, and this adjustment was checked at the end of the experiment. Two experi- ments were discarded because of a greater than $3 \mathrm{mv}$ drift in the base line during the course of the experiment. Perfusion pipettes with relatively large bores (I.D. $=20 \mu$ ) were advanced at least $500 \mu$ down the lumen of the tubule to give adequate electrical seal at the perfusion end. The tip resistances ranged from 4 to $7 \mathrm{M} \Omega$. In these experiments the rate of perfusion was governed by hydrostatic pressure of the perfusion fluid and was varied from $30 \mathrm{nl} \min ^{-1}$ to such a low flow rate that the tubule tended to collapse around the inner perfusion pipette.

Net fluid transport was measured at slow perfusion rates, $6.21 \pm 0.35 \mathrm{nl} \mathrm{min}{ }^{-1}$, using the same bath and perfusion solution as that in the transmembrane potential measurements. Albumin ${ }^{125} \mathrm{I}$ was added to the perfusion solution to give final counts ranging from 40 to $80 \mathrm{cpm} / \mathrm{nl}$. Perfusion rate $\left(V_{1}\right)$, collection rate $\left(V_{0}\right)$, and absolute reabsorption were calculated from concentration changes in collected ${ }^{125} \mathrm{I}$ by equations previously published by Burg and Orloff (4):

$$
\mathrm{C}=\frac{\mathrm{V}_{\mathrm{i}}-\mathrm{V}_{\mathrm{o}}}{\mathrm{L}}
$$

where $V_{1}$ is calculated by dividing the ${ }^{125} \mathrm{I}$ cpm of the collected fluid by ${ }^{125} \mathrm{I} \mathrm{cpm} / \mathrm{nl}$ of perfusion fluid and by time of the collection period. $V_{0}$ is obtained directly by a calibrated constant bore collection pipette. $\mathrm{L}$ is the length of the tubule, and $\mathrm{C}$ is the absolute volume of fluid transported in $\mathrm{nl} \mathrm{mm} \mathrm{mm}^{-1} \mathrm{~min}^{-1}$ and is positive if fluid is absorbed and negative if fluid is secreted.

The total radioactivity secondary to albumin $-{ }^{125} \mathrm{I}$ in each collected sample varied from 4000 to 15,000 counts per 10 min. The samples routinely were preset for 10 -min counts. If $10 \%$ of the label were lost into the bath during the $10-\mathrm{min}$ collection period, then the total bath counts would vary from 400 to 1500 counts per $10 \mathrm{~min}$. However, when the total bath was counted, there were no detectable counts. It is therefore felt that albumin ${ }^{-125} I$ is a suitable volume marker. Tissue uptake of albumin- ${ }^{125}$ I could be only a trivial source of error, since each tubule is perfused for $20 \mathrm{~min}$ before the first collection. Thus, there is more than adequate time for equilibration of albumin ${ }^{-25} I$ in a tissue with less than $1 \mathrm{nl}$ total volume.

Passive permeability coefficient for ${ }^{22} \mathrm{Na}\left(\mathrm{P}_{\mathrm{xa}_{\mathrm{a}}}\right)$ was estimated from the disappearance rate of ${ }^{22} \mathrm{Na}$ from the perfusion fluid. The perfusion fluid, which was isomolal ultrafiltrate of the same rabbit serum as used in the bath, was perfused at a mean rate of $19.6 \pm 0.4 \mathrm{nl} \mathrm{min}{ }^{-1}$. The passive 
permeability coefficient of $\mathrm{Na}$ was estimated according to the following expression (5):

$$
\mathrm{P}_{\mathrm{Na}}=\frac{\mathrm{V}_{\mathrm{i}}}{\mathrm{A}} \ln \frac{\mathrm{C}_{\mathrm{i}}{ }^{*}}{\mathrm{C}_{\mathrm{o}}^{*}}
$$

where $\mathrm{A}=$ area of tubule, $\mathrm{V}_{1}=$ perfusion rate, $\mathrm{C}_{1} *=$ $\mathrm{cpm} / \mathrm{nl}$ of ${ }^{22} \mathrm{Na}$ in perfusion fluid, and $\mathrm{C}_{\mathrm{o}}{ }^{*}=\mathrm{cpm} / \mathrm{nl}$ of ${ }^{22} \mathrm{Na}$ in the collected fluid. This equation is applicable when $\mathrm{J}_{\mathbf{v}}=0$ and gives the passive permeability of ${ }^{22} \mathrm{Na}$ in both directions in absence of active transport.

The reflection coefficient, $\sigma$, as defined by Staverman (6), is equal to

$$
\sigma=\pi \text { observed } / \pi \text { theoretical }
$$

where $\pi$ equals the osmotic pressure secondary to solute in question. This operational definition indicates the effectiveness of a solute in generating an osmotic pressure across a membrane as compared with an equivalent concentration of an ideal nonpenetrating molecule. Kedem and Leaf (7) have shown that this definition of $\sigma$ is applicable for either nonelectrolytes or electrolytes, provided the electrolyte is treated as a single electronically neutral component; under these conditions the electrical field across the membrane may be neglected. A completely permeant compound cannot exert any osmotic force and would have $\sigma=0$, while a completely impermeant compound would exert its theoretical osmotic pressure and have $\sigma=1$. In these experiments the reflection coefficient of raffinose is assumed to equal 1.0, since Marsh and Solomon (8) have shown by the split-drop technique that raffinose is completely impermeant in the DLH. Further justification for this assumption comes from our experiments where it was noted that over $99 \%$ of perfused mannitol- $-{ }^{14} \mathrm{C}$ could be accounted for in the collected fluid when it was added to the perfusion fluid of isosmolal ultrafiltrate. Unfortunately, labeled raffinose is not available, but it is reasonable to expect that raffinose with a molecular weight of 594 is less permeant than mannitol with a molecular weight of 182 .

$\sigma \mathrm{NaCl}$ was determined from experiments in which the perfusion solution was sodium-free and contained $293 \mathrm{mOsin}$ of raffinose, $5 \mathrm{~mm} \mathrm{KCl}, 1 \mathrm{~mm} \mathrm{MgCl}_{2}$, and $1 \mathrm{mM} \mathrm{CaCl}_{2}$. Control periods were obtained by perfusing with isosmolal raffinose solution against a bath of rabbit serum. Average

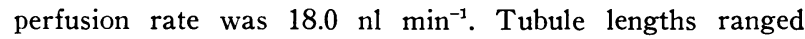
from 0.90 to $1.36 \mathrm{~mm}$, with a mean length of $1.20 \mathrm{~mm}$. During these periods there was a net influx of water owing
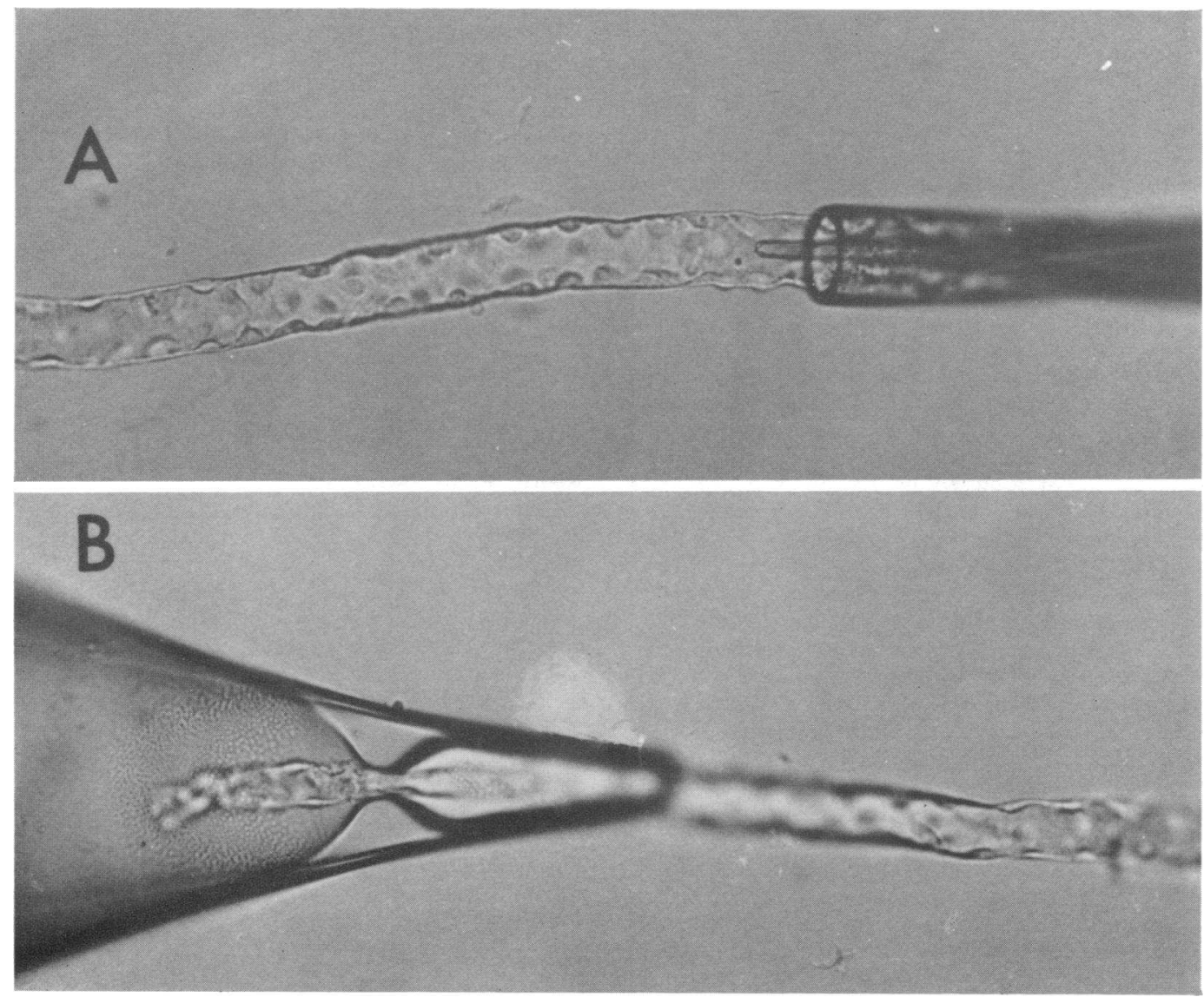

Figure 2 Photograph of the perfusion and collection end of a thin descending limb of Henle $(\times 100)$. A shows how the tubule appears at the perfusion end. Note that all of the pars recta is sucked into the constriction of the holding pipette, providing a good tissue-glass seal. $B$ demonstrates the manner in which Sylgard-184 lightly constricts the tubule to provide excellent electrical seal. 


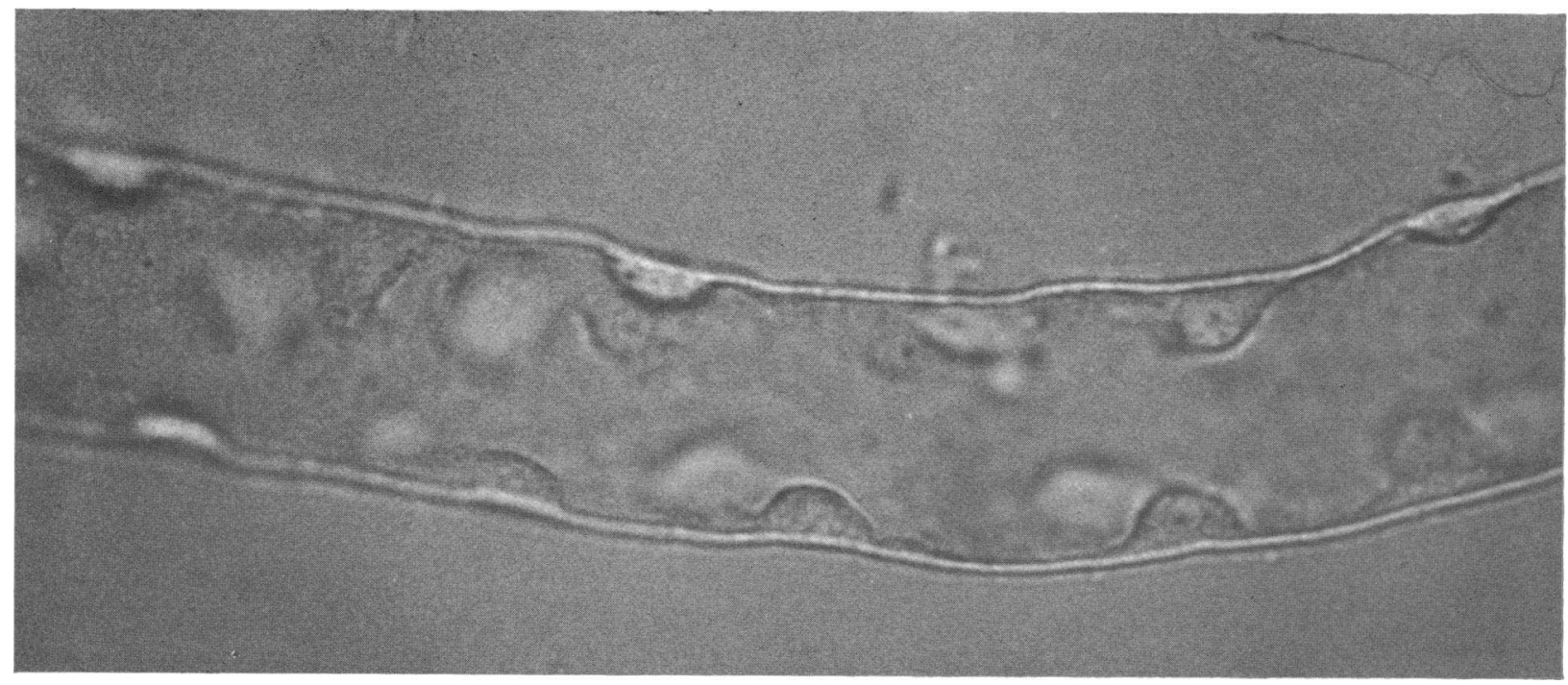

FIgURE 3 Magnification $(\times 400)$ of a perfused descending limb of Henle. From this it is evident that the outside and inside diameters are approximately the same. Only the nucleus of the squamous epithelium protrudes into the lumen. The cytoplasm appears quite clear, without granular material at the magnification.

to the higher effective osmolality of the perfusion solution. $\mathrm{NaCl}$ was then added to the bath for a final osmolality of 407. This reversed the net transport of fluid. Conditions of zero flow were obtained by interpolation between the control and hyperosmotic points. The $\sigma \mathrm{NaCl}$ at $\mathrm{J}_{\mathbf{v}}=0$ is $\Delta \pi$ raffinose $/ \Delta \pi \mathrm{NaCl}$, where $\Delta \pi$ raffinose is equal to the osmotic pressure of the luminal fluid. $\Delta \pi \mathrm{NaCl}$ is the osmotic pressure of the bath corrected for the mean osmotic pressure secondary to $\mathrm{NaCl}$ in the intraluminal fluid. The mean intraluminal $\mathrm{NaCl}$ concentration was assumed to be one-half the measured chemical $\mathrm{NaCl}$ concentration of the collected fluid. The osmolality due to $\mathrm{NaCl}$ was then approximated by multiplying the mean intraluminal concentration by the osmotic coefficients for $\mathrm{NaCl}$.

Hydraulic conductivity of water $\left(\mathrm{L}_{p}\right)$ was determined by measuring net fluid movement in response to imposed osmotic gradients. During the control period the perfusion fluid was isosmolal ultrafiltrate of the same rabbit serum as that in the bath. Net fluid movement was then induced by addition of either $100 \mathrm{mOsm}$ of raffinose or $\mathrm{NaCl}$ to the bath. Rapid perfusion rates and short segments, average length $472 \mu$, of tubules were chosen so that osmotic equilibration was not complete. Osmolality of the collected fluid was measured, and the logarithmic mean osmotic gradient between the bath and the collected fluid was obtained by use of semi-log paper. $L_{p}$ was calculated in each case by the following equation:

$$
\mathrm{L}_{\mathrm{p}}=\frac{\mathrm{J}_{\mathrm{v}}}{\pi \mathrm{B} / \mathrm{P}}
$$

where $\pi \mathrm{B} / \mathrm{P}$ is the logarithmic mean of the osmotic pressure difference between the bath and perfusion fluid. $J_{v}$ is the net induced water flow between the control and hyperosmotic periods.

Human albumin- ${ }^{125} \mathrm{I}$, which was routinely used as the volume marker, was purchased from E. R. Squibb \& Sons (New York) and concentrated to contain approximately $300 \mu \mathrm{Ci} / \mathrm{cm}^{3}$ by the use of Aminco (American Instrument
Co., Inc., Silver Spring, Md.) pressure dialysis using PM-10 filters. Before use it was dialyzed in a cellophane bag against a Ringer's solution to minimize the free ${ }^{125} \mathrm{I}$. ${ }^{22} \mathrm{Na}$ was obtained from International Chemical \& Nuclear Corporation, Burbank, Calif.). All isotopic counting was done on a Packard Model 3003 three-channel autogamma spectrometer (Packard Instrument Co., Inc., Downers Grove, I11.). The ultrafiltrate of rabbit serum was made by pressure dialysis using Aminco PM-50 membranes. The osmolality of the collected fluid was determined by a Clifton nanoliter osmometer (Clifton Technical Physics, New York), in which the sample plate had been modified to obtain more reproducible measurements. The chemical $\mathrm{Na}$ of the collected fluid was determined by Aminco Helium glow photometer. All results are expressed as mean \pm standard error.

\section{RESULTS}

Active transport was evaluated by perfusing tubule segments ranging in length from 1.05 to $2.80 \mathrm{~mm}$ at rates of $6.21 \pm 0.35 \mathrm{nl} \mathrm{min}^{-1}$ using isosmolal ultrafiltrate of the same rabbit serum as the bath. (The mean luminal diameter was $27 \pm 0.07 \mu$.) Net transport in six consecutive experiments ( 18 collections) was $-0.07 \pm 0.06$

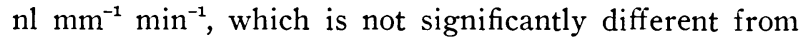
zero (Table I). The collected fluid $\mathrm{Na}$ concentration was $142.8 \pm 3.2 \mathrm{mEq} /$ liter as compared with a bath $\mathrm{Na}$ concentration of $144.9 \mathrm{mEq} /$ liter.

Transmembrane potential was $-0.83 \pm 0.28 \mathrm{mv}$ ( $\mathrm{n}$ $=6$; lumen negative) using the same perfusion solution and bath as was used to evaluate net transport (Table I).

Passive permeability. Sodium permeability was measured isotopically using isosmolal ultrafiltrate as the perfusion fluid. The bath was rabbit serum. Net fluid 
TABLE I

Membrane Characteristics of the Thin Descending Limb of Henle

Net transport of fluid (C)

Transmembrane potential (PD)

Passive permeability coefficient for $\mathrm{NaCl}\left(\mathrm{P}_{\mathrm{Nu}}\right)$

Hydraulic conductivity $\left(\mathrm{L}_{\mathrm{p}}\right)$

Reflection coefficient for $\mathrm{NaCl}$ $(\sigma \mathrm{NaCl})$

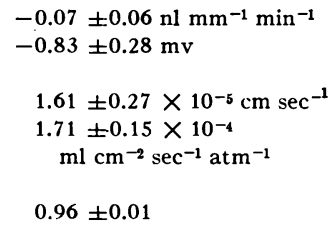

movement was zero, while the mean perfusion rate was $19.6 \pm 0.4 \mathrm{nl} \min ^{-1}(\mathrm{n}=6)$. The short contact times and impermeability of the membrane allowed only $6.4 \%$ of the intraluminal sodium to exchange with the bath; however, significant differences were obtained in cpm of ${ }^{22} \mathrm{Na}$ between perfusion and collected fluids. Under these conditions $P_{\mathrm{Na}}$ was $1.61 \pm 0.27 \times 10^{-5} \mathrm{~cm}$ $\sec ^{-1}(\mathrm{n}=6)$ (Table I).

Reflection coefficients. The reflection coefficient for $\mathrm{NaCl}$ was measured by determining that concentration of $\mathrm{NaCl}$ in the bath at which the net transport of fluid was zero when perfusing with 309 mOsm of $\mathrm{Na}$-free raffinose solution. In these experiments there was a net entry of $\mathrm{NaCl}$ ranging from 10.9 to $33.1 \mathrm{mEq} /$ liter with a mean of $19.1 \mathrm{mEq} /$ liter when the bath was

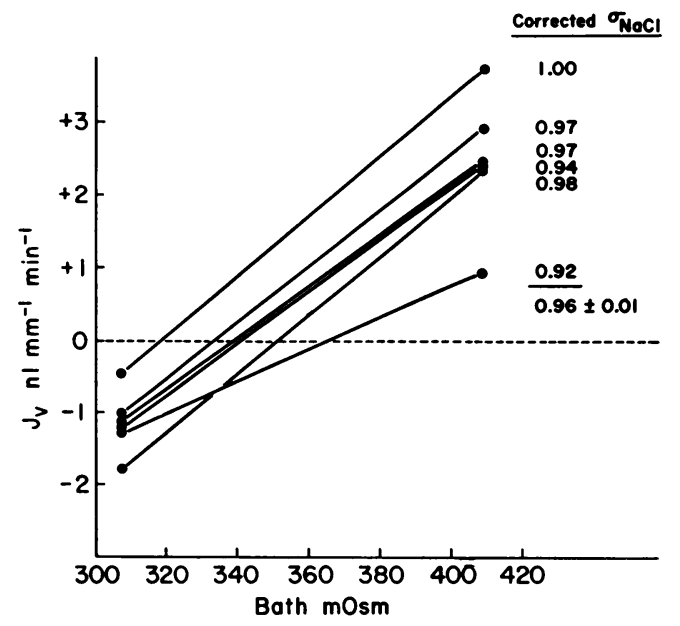

FIgURE 4 Measurement of reflection coefficient for $\mathrm{NaCl}$ in the thin descending limb of Henle. Net water flow, $\mathrm{J}_{v}$, is represented on the coordinate. Negative values indicate influx of water into the lumen, while positive values represent abstraction of fluid from the nephron. The abscissa represents the osmolarity of the bath. Osmolarity of the perfusion fluid is 309. Each dot represents an average of three collection periods in an individual tubule. A line is drawn to connect the "control" and "experimental" points of the same tubule. Zero flow is obtained from the point at which the line intersects the horizontal axis. Corrected $\sigma \mathrm{NaCl}$ is calculated by methods described in the text.
309 mOsm of rabbit serum; when the bath concentration of $\mathrm{NaCl}$ was raised by $100 \mathrm{mOsm} /$ liter, the $\mathrm{Na}$ concentration in the collected fluid ranged from 12.7 to $47.2 \mathrm{mEq} /$ liter with a mean of $27.3 \mathrm{mEq} /$ liter. Onehalf of the collected $\mathrm{NaCl}$ concentration was subtracted from bath $\mathrm{NaCl}$ to give $\Delta \pi \mathrm{NaCl}$. At $\mathrm{J}_{\mathbf{v}}=0, \sigma \mathrm{NaCl}$ $=\Delta \pi$ raffinose $/ \Delta \pi \mathrm{NaCl}$. The individual experimental results are depicted in Fig. 4.

The approximate $5 \%$ error in the estimation of $\sigma \mathrm{NaCl}$ arises from the correction factors used to calculate $\sigma \mathrm{NaCl}$. Two assumptions account for the dual finding of some variability in the means and the very low standard error for each mean. First, the correction of the magnitude of $\mathrm{NaCl}$ gradient by estimation of the geometric mean intratubular concentration approximates, but cannot exactly equal, the $\mathrm{NaCl}$ gradient along the course of the measured length of DLH. Second, the assumption that the average raffinose concentration along the length of perfused tubule is the same as the perfusate is not exactly true in every instance. For example, when the bath is $309 \mathrm{mOsm} /$ liter, there is net secretion of fluid and dilution of the raffinose, while with a hyperosmotic bath water is abstracted and the raffinose concentrated. The sources of error may be best exemplified by considering the raw data from a single experiment (Table II). If these values are substituted into the flow equation of Kedem and Katchalsky (9) $\mathrm{J}_{\mathbf{v}}=-\mathrm{L}_{\mathrm{p}}(\pi$ raffinose $-\sigma \mathrm{NaCl} \pi \mathrm{NaCl})$, the $\sigma \mathrm{NaCl}$ may be solved for directly since the other parameters are

TABLE II

Data from a Typical Single $\mathrm{NaCl}$ Reflection Coefficient Experiment

Length: $1.28 \mathrm{~mm}$; inside diameter: $28 \mu$; area : $11.3 \times 10^{-4}$ $\mathrm{cm}^{2}$; area/mm: $8.84 \times 10^{-4} \mathrm{~cm}^{2}$; perfusion fluid: $293 \mathrm{mOsm}$ of raffinose; $5 \mathrm{~mm} \mathrm{KCl} ; 1 \mathrm{~mm} \mathrm{CaCl} 2 ; 1 \mathrm{~mm} \mathrm{MgCl}_{2}$

\begin{tabular}{|c|c|c|}
\hline $\begin{array}{l}\text { Bath } \\
\text { No. } 1\end{array}$ & Experimental data & $\begin{array}{l}\text { Bath } \\
\text { No. } 2\end{array}$ \\
\hline 15.9 & $\mathrm{~V}_{i}\left(\mathrm{nl} \min ^{-1}\right)$ & 17.7 \\
\hline-1.12 & 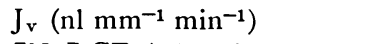 & 2.56 \\
\hline 19.9 & {$[\mathrm{Na}] \mathrm{CF}\left(\mathrm{mEq}\right.$ liter $\left.^{-1}\right)$} & 15.8 \\
\hline 312 & CF osmolality (mOsm) & 403 \\
\hline 275 & mean $\Delta \pi \mathrm{NaCl}$ (mOsm) & 379 \\
\hline 282 & mean $\Delta \pi$ raffinose $(\mathrm{mOsm})$ & 313 \\
\hline
\end{tabular}

The mean $\Delta \pi$ raffinose of the intraluminal fluid is not the same as that of the collected fluid but may be represented as the logarithmic mean between the concentration of raffinose in the perfusion fluid and collection fluid. The mean $\Delta \pi \mathrm{NaCl}$ is obtained by subtracting one-half the $\mathrm{NaCl}$ osmolality in the collection fluid from the respective $\mathrm{MaCl}$ osmolalities of the two bathing media. CF = collected fluid. Bath No. 1 is rabbit serum, $309 \mathrm{mOsm}$. Bath No. 2 is $309 \mathrm{mOsm}$ of rabbit serum plus $100 \mathrm{mOsm}$ of $\mathrm{NaCl}$ for total osmolality of 409 . 
known. The independently determined $\mathrm{L}_{\mathrm{p}}$ of $1.71 \times 10^{-4}$ $\mathrm{ml} \mathrm{cm} \mathrm{sec}^{-1} \mathrm{~atm}^{-1}$ will be used in the solution of this equation. $\sigma \mathrm{NaCl}$ equals 1.00 , using the values from the experiments in which the bath was isosmolal, and 0.86 , using the data from the experiments where hyperosmolal bath was used. The discrepancies in all probability arise from the correction factors used. As will be noted, the $\sigma \mathrm{NaCl}$ of 0.96 is in close agreement with 1.00 as calculated from the isosmolal conditions. This is to be expected since under these conditions the percentage transport of fluid is less than when hyperosmolar serum is used. Additional lines of evidence which heavily favor the higher $\sigma \mathrm{NaCl}$ are obtained from the experiments, presented below, where the osmotically induced water flow is the same when equiosmolal quantities of $\mathrm{NaCl}$ or raffinose are used as the osmotic gradient. The two independent lines of evidence strongly support the validity of the high $\sigma \mathrm{NaCl}$ calculated by the simple assumptions presented, but the sources of error are recognized.

Osmotic water permeability. The hydraulic conductivity $\left(L_{p}\right)$ was calculated from experiments where net water movement was induced by addition of $100 \mathrm{mOsm} /$ liter of raffinose or $\mathrm{NaCl}$ to the bath. By perfusing short tubules, $472 \pm 24 \mu$ in length, $(n=12)$ at a fast per-

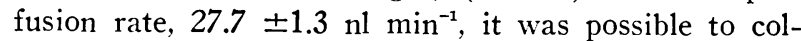
lect perfusate before osmotic equilibration took place. In control periods the osmolality of the ultrafiltrate was 309, which was the same as the bath of rabbit serum. The osmolality of the bath was 407 in each case when raffinose or $\mathrm{NaCl}$ was added to the bath. The osmolality of the collected fluid then ranged from 355 to 396 with a mean osmolality of $379 \pm 3.4$. The mean $\mathrm{L}_{\mathrm{p}}$ was 1.71 $\pm 0.15 \times 10^{-4} \mathrm{ml} \mathrm{cm} \mathrm{sec}^{-1} \mathrm{~atm}^{-1} \quad(\mathrm{n}=6) \quad($ Table I) when the bath was made hyperosmolal by addition of
$100 \mathrm{mOsm} /$ liter of raffinose and $1.62 \pm 0.05 \times 10^{-4} \mathrm{ml}$ $\mathrm{cm}^{-2} \mathrm{sec}^{-1}$ atm $^{-1}(\mathrm{n}=6)$ when $100 \mathrm{mOsm} /$ liter of $\mathrm{NaCl}$ was added to the bath. In the experiments where the bath hyperosmolality was achieved by the addition of $\mathrm{NaCl}$ (Table III), the mean osmolality of the collection fluid increased by $69.7 \pm 3.5 \mathrm{mOsm}$ or $22.5 \pm 1.2 \%$. In these same experiments there was a net efflux of water which amounted to $22.3 \pm 0.7 \%$ of the perfusion rate.

The validity of the results thus far presented depends on the viability of the artificially perfused descending limb of Henle. Specifically, active transport of $\mathrm{NaCl}$ has been ruled out, and the absence of transmembrane potential leaves one wondering if the tissue is dead. It is impractical to measure oxygen consumption of a single perfused tubule since its total weight is less than $1 \mathrm{ng}$. To test the viability of DLH the effects of cyanide were tested. First, when $10^{-2} \mathrm{M} \mathrm{NaCN}$ was added to the bath, the cells were noted to become granular and nuclei pyknotic. Second, when $0.25 \%$ Trypan blue is added to the bath, cells of the perfused DLH become stained in the presence of cyanide but not in its absence. Staining with Trypan blue is routinely used as an index of viability in lymphocyte experiments-viable cells not staining, while dead cells take up the dye. The third line of evidence to indicate that the isolated perfused DLH is alive arises from permeability studies. It is generally accepted that tissue becomes more permeable with death. It would be unusual to find the DLH as impermeable to ${ }^{22} \mathrm{Na}$ as reported here if it were not viable. Three separate experiments were conducted in which ${ }^{22} \mathrm{Na}$ permeability was measured in the presence and absence of $10^{-2} \mathrm{M} \mathrm{NaCN}$. After a $10 \mathrm{~min}$ exposure to $\mathrm{NaCN}$, the tubule became markedly more permeable to ${ }^{22} \mathrm{Na}$; and during the third collection period, $\mathrm{Na}$

TABLE III

The Relationship between Per Cent Increase in Osmolarity of the Collected Fluid to Per Cent Reabsorption of Fluid when the Bath is Made Hyperosmolar by Addition of $100 \mathrm{mOsm}$ of $\mathrm{NaCl}$

\begin{tabular}{|c|c|c|c|c|c|c|c|c|}
\hline $\begin{array}{l}\text { Exp. } \\
\text { No. }\end{array}$ & Length & Area & $\mathrm{V}_{\mathrm{i}}$ & $\mathrm{Jv}_{\mathrm{v}}$ & $\begin{array}{l}\text { Collection } \\
\text { fluid }\end{array}$ & $\begin{array}{c}\% \\
\text { Increase in } \\
\text { collection } \\
\text { fluid }\end{array}$ & $\begin{array}{c}\% \\
\text { Reabsorp. } \\
\text { of fluid }\end{array}$ & $\mathrm{L}_{p}$ \\
\hline & $\mu$ & $\mathrm{cm}^{2} \times 10^{-4}$ & $n l \min ^{-1}$ & $n l \mathrm{~mm}^{-1} \min ^{-1}$ & $m O s m$ & $m O s m$ & & $\begin{array}{c}m l \mathrm{~cm}^{-2} \mathrm{sec}^{-1} \mathrm{alm}^{-1} \\
\times 10^{-4}\end{array}$ \\
\hline 1 & 460 & 4.18 & 28.10 & 6.65 & 370 & 19.7 & 23.7 & 1.71 \\
\hline 2 & 536 & 4.54 & 27.16 & 6.66 & 366 & 18.4 & 24.5 & 1.48 \\
\hline 3 & 560 & 6.15 & 29.78 & 6.65 & 391 & 26.5 & 22.3 & 1.72 \\
\hline 4 & 545 & 5.65 & 29.87 & 6.97 & 384 & 24.3 & 23.3 & 1.71 \\
\hline 5 & 419 & 5.39 & 32.19 & 6.55 & 376 & 21.7 & 20.3 & 1.42 \\
\hline 6 & 335 & 3.16 & 23.67 & 4.60 & 385 & 24.6 & 19.4 & 1.68 \\
\hline \multicolumn{2}{|c|}{ Mean $\pm \mathrm{SE}$} & & & & & $22.5 \pm 1.2$ & $22.3 \pm 0.7$ & $1.62 \pm 0.05$ \\
\hline
\end{tabular}

Control experiments were obtained using isosmolal ultrafiltrate of same rabbit serum as the bath. $\mathrm{J}_{\mathrm{v}}$ is the difference in fluid reabsorption between control periods and when $100 \mathrm{mOsm}$ of $\mathrm{NaCl}$ was added to the bath. $\mathrm{V}_{\mathrm{i}}=$ perfusion rate (average of three collection periods), $\mathrm{L}_{\mathrm{p}}=$ hydraulic conductivity of water. 
permeability had increased by over an order of magnitude. It is difficult to quantitate the increase in $\mathrm{Na}$ permeability to any greater degree than the general comments made since a new steady level of permeability was never reached. In each collection period the tubule became more permeable than in the previous period. These three lines of evidence strongly support the thesis that the tubule is viable.

\section{DISCUSSION}

The present studies provide further information concerning the role of the descending limb of Henle in the countercurrent multiplication system. Several lines of evidence indicate that the DLH does not actively transport $\mathrm{NaCl}$. First, it was shown that the tubule is unable to transport net amounts of fluid in the absence of osmotic gradients. This finding is in agreement with the earlier in vivo studies of Marsh and Solomon (8), where they were able to show by the split-drop technique that the thin descending limb is not able to transport net amounts of fluid. Also, Morgan and Berliner (10) have shown that $\mathrm{TF} / \mathrm{P}$ inulin does not change when the descending limb is perfused with solutions isosmotic to the medullary interstitium. Active salt transport might not be apparent from these techniques if the descending limb were sufficiently impermeable to water to prevent the reabsorption of the split drop or change in observed $\mathrm{TF} / \mathrm{P}$ inulin. In the latter hypothesis if active salt transport were occurring in a relatively water-impermeable DLH, there should be a progressive decrease in $\mathrm{NaCl}$ concentration of the intraluminal fluid. In the present studies, the $\mathrm{NaCl}$ concentration in the collected fluid did not differ significantly from the bath $\mathrm{NaCl}$, indicating that the thin limb of Henle cannot generate $\mathrm{NaCl}$ concentration gradients as has been hypothesized for the ascending thin limb. In the case of frog skin it is difficult to show net transport of fluid; however, the skin is able to transport $\mathrm{Na}$ actively as shown by the existence of transmembrane potential and short-circuit current (11). We therefore measured the transmembrane potential of the DLH and found it not to differ significantly from zero. On the basis of these results it appears that the isolated DLH does not actively transport salt; and hence, if it has the same properties in vivo as in vitro, then the DLH does not appear to play a role in generating medullary hypertonicity, but rather, it functions primarily as a passive equilibrating segment.

Numerous investigators (12-15) have found that the osmolality of the intratubular fluids becomes progessively hyperosmotic from the corticomedullary junction to the papilla. Disagreement, however, has arisen as to whether this occurs primarily by abstraction of fluid or by influx of solute. Lassiter, Gottschalk, and
Mylle (16) and Gottschalk et al. (12) have found that the DLH fluid to plasma inulin concentrations of $\mathrm{TF} / \mathrm{P}$ inulin was approximately 11 , which was much higher than in the last accessible part of the proximal convoluted tubule (PCT). This would suggest that fluid in the DLH becomes hypertonic primarily by abstraction of water. Recently de Rouffignac and Morel (17) have presented conflicting results and have suggested that $85 \%$ of the concentration in the DLH occurs by influx of solute, primarily $\mathrm{NaCl}$.

Quantitation of volume reabsorption in the DLH from measured $\mathrm{TF} / \mathrm{P}$ inulin values is hazardous since the $\mathrm{TF} / \mathrm{P}$ inulin at the end of the pars recta cannot be determined by conventional micropuncture techniques. Recently, Marsh (18) has overcome this objection by puncturing the DLH at different levels. He measured the $\mathrm{TF} / \mathrm{P}$ inulin and $\mathrm{TF} / \mathrm{P}$ osmolality at these two puncture sites and concluded that both of these values increased by the same fractional amount in the more distal site. Though his (18) changes in $T F / P$ values were small, they suggest that fluid abstraction is more significant than solute influx.

To completely evaluate the process of osmotic equilibration in the DLH it is necessary to determine the relative permeabilities to $\mathrm{NaCl}$ and water. No direct measurements of isotopic permeability to $\mathrm{NaCl}$ have been made, though indirect studies of de Rouffignac and Morel (19) would suggest high $\mathrm{Na}$ permeability in the DLH. They concluded from previous studies, in which ${ }^{22} \mathrm{Na}$ was injected into PCT and its disappearance rate was monitored in the urine, that the walls of the thin limb of Henle are quite permeable to sodium. This type of study makes the assumption that the pars recta is relatively impermeable to $\mathrm{NaCl}$, which is in contrast to current thinking.

Direct measurements of $\mathrm{P}_{\mathrm{Na}}$ of the DLH in the present studies do not support the view of de Rouffignac and Morel. The $P_{\mathrm{Na}}$ value of $1.61 \times 10^{-5} \mathrm{~cm} \mathrm{sec}^{-1}$ is approximately 5-6 times less than the value in the proximal convoluted tubule. ${ }^{1}$ Further evidence that the DLH is relatively impermeable to $\mathrm{NaCl}$ is the high vaue for $\sigma \mathrm{NaCl}(0.96)$. This is in contrast to the much lower $\sigma \mathrm{NaCl}$ reported for the PCT (20-22). The high $\sigma \mathrm{NaCl}$ is consistent with the low isotopic permeability to $\mathrm{NaCl}$ and indicates $\mathrm{NaCl}$ is able to generate a high effective osmotic pressure. It also suggests that solvent drag of $\mathrm{NaCl}$ is minimal in this segment. It has been pointed out by Gottschalk and Mylle (15) that the $\mathrm{L}_{\mathrm{p}}$ in DLH should be high since apparent osmotic equilibration between the vasa recta and luminal fluid takes place. The direct measurements presented here are consistent

\footnotetext{
${ }^{1}$ Kokko, J. P., M. B. Burg, and J. Orloff. 1970. Characteristics of $\mathrm{NaCl}$ and water transport in the renal proximal tubule. Submitted for publication.
} 
with the hypothesis put forth by Gottschalk and Mylle (15) and also are in agreement with the high water permeability demonstrated by Morgan and Berliner (10). The high $\mathrm{L}_{\mathrm{p}}$ of $1.71 \pm 0.15 \times 10^{-4} \mathrm{ml} \mathrm{cm}^{-2} \mathrm{sec}^{-1}$ $\mathrm{atm}^{-1}$ shows that the thin descending limb has much higher permeability to osmotic flow of water than previously had been found for the PCT (23). ${ }^{1}$ Two qualifications must be made. These studies represent step functions, whereas the loop experiences osmotic gradients which are in linear differential increments. Under the current experimental conditions it was not practical to use shorter segments or smaller gradients. However, it is estimated that the net osmotic gradient of $100 \mathrm{mOsm}$ induced for a mean length of $472 \mu$ of DLH is approximately the same as seen by equivalent lengths of descending limb in vivo in a nondiuretic animal. The second qualification is that our studies were primarily performed at normal serum concentrations. It is possible that some of the coefficients measured in these studies may change in hyperosmotic surroundings; however, the hypothesized changes are not expected to be of major magnitude.

We next examined how the determined parameters, high $\mathrm{L}_{\mathrm{p}}$, high $\sigma \mathrm{NaCl}$, and low sodium permeability, are operative in concentrating the intraluminal fluid. These studies were performed by perfusing with 309 mOsm of ultrafiltrate against a bath made hyperosmotic by addition of $100 \mathrm{mOsm}$ of $\mathrm{NaCl}$. As summarized in Table III the omolality of the collected fluid increased by $22.5 \%$, while the net efflux of water was equal to $22.3 \%$ of the perfusion rate. Thus, it can be seen that the concentration of the descending loop fluid occurs almost entirely by abstraction of water without significant net entry of $\mathrm{NaCl}$.

In summary, these studies show that the isolated descending loop of Henle does not actively transport $\mathrm{NaCl}$ and therefore does not contribute to generation of medullary hypertonicity; instead, it appears to serve entirely as a passive equilibrating segment. The combination of high osmotic permeability to water and low permeability to $\mathrm{Na}$ is consistent with the hypothesis that high interstitial concentration of $\mathrm{Na}$ in the medulla generates an effective osmotic pressure which results in concentration of the fluid as it comes through the DLH primarily by abstraction of water without significant net entry of $\mathrm{NaCl}$.

\section{ACKNOWLEDGMENTS}

This research was supported by U. S. Public Health Service Program Grant PO1 HE11662 and the Dallas Heart Association.

\section{REFERENCES}

1. Burg, M., J. Grantham, M. Abramow, and J. Orloff. 1966. Preparation and study of fragments of single rabbit nephrons. Amer. J. Physiol. 210: 1293.
2. Helman, S. I., and J. J. Grantham. 1969. Effect of ADH on electrical membrane resistance in isolated cortical collecting tubules. Fed. Proc. 28: 524.

3. Burg, M. B., L. Isaacson, J. Grantham, and J. Orloff. 1968. Electrical properties of isolated perfused rabbit renal tubules. Amer. J. Physiol. 215: 788.

4. Burg, M. B., and J. Orloff. 1968. Control of fluid absorption in the renal proximal tubule. J. Clin. Invest. 47: 2016.

5. Grantham, J. J., and M. B. Burg. 1966. Effect of vasopressin and cyclic AMP on permeability of isolated collecting tubules. Amer. J. Physiol. 211: 255.

6. Staverman, A. J. 1951. The theory of measurement of osmotic pressure. Rec. Trav. Chim. Pays-Bas. 70: 344.

7. Kedem, O., and A. Leaf. 1966. The relation between salt and ionic transport coefficients. J. Gen. Physiol. 49: 655.

8. Marsh, D. J., and S. Solomon. 1965. Analysis of electrolyte movement in thin Henle's loops of hamster papilla. Amer. J. Physiol. 208: 1119.

9. Kedem, O., and A. Katchalsky. 1958. Thermodynamic analysis of the permeability of biological membranes to non-electrolytes. Biochim. Biophys. Acta. 27: 229.

10. Morgan, T., and R. W. Berliner. 1968. Permeability of the loop of Henle, vasa recta, and collecting duct to water, urea, and sodium. Amer. J. Physiol. 215: 108.

11. Ussing, H. H., and K. Zeraka. 1951. Active transport of sodium as the source of electric current in the shortcircuited isolated frog skin. Acta Physiol. Scand. 23: 110.

12. Gottschalk. C. W., W. E. Lassiter, M. Mylle, K. J. Ullrich, B. Schmidt-Nielsen, R. O'Dell, and G. Pehling. 1963. Micropuncture study of composition of loop of Henle fluid in desert rodents. Amer. J. Psysiol. 204: 532.

13. Wirz, H., B. Hargitay, and W. Kuhn. 1951. Lokalisation des Konzentrierungsprozesses in der Niere durch direkte Kryoskopie. Helv. Physiol. Pharmacol. Acta. 9: 196.

14. Ullrich, K. J., F. O. Drenckhan, and K. H. Jarausch. 1955. Untersuchungen zum Problem der Harkonzentrierung und Verdünnung. Uber das osmotische Verhalten von Nierenzellen und die begleitende Elektrolytanhäufung in Nierengewebe bei verschiedenen Diuresezustanden. Pfluegers Arch. Gesamte Physiol. Menschen Tiere. 261: 62 .

15. Gottschalk, C. W., and M. Mylle. 1959. Micropuncture study of the mammalian urinary concentrating mechanism: evidence for the countercurrent hypothesis. Amer. J. Physiol. 196: 927.

16. Lassiter, W. E., C. W. Gottschalk, and M. Mylle. 1961. Micropuncture study of net transtubular movement of water and urea in non-diuretic mammalian kidney: Amer. J. Physiol. 200: 1139.

17. de Rouffignac, C., and F. Morel. 1969. Micropuncture study of water, electrolytes and urea movements along the loops of Henle in Psammomys. J. Clin. Invest. 48: 474.

18. Marsh, D. J. 1970. Solute and water flow in thin limbs of Henle's loop in the hamster kidney. Amer. J. Physiol. 218: 824.

19. de Rouffignac, C., and F. Morel. 1967. La perméabilité au sodium des différents segments du nephron étudié 
chez le rat en diurèse saline a l'tide de microinjections intratubulaires de ${ }^{22} \mathrm{Na}$. Nephron. 4: 92.

20. Kokko, J. P., and M. B. Burg. 1969. Reflection coefficient for $\mathrm{NaCl}$ in proximal renal tubules. Fed. Proc. 28: 589.

21. Ullrich, K. J., G. Rumrich, and B. Schmidt-Nielsen. 1967. Reflection coefficient of different nonelectrolytes in the proximal convolution of the rat kidney. Fed. Proc. 26: 375 .
22. Rector, F. C., Jr., M. Martinez-Maldonado, F. P. Brunner, and D. W. Seldin. 1966. Evidence for passive reabsorption of $\mathrm{NaCl}$ in proximal tubule of rat kidney. J. Clin. Invest. 45: 1060.

23. Ullrich, K. J., G. Rumrich, and G. Fuchs. 1964. Wasserpermeabilität und transtubularer wasserfluss corticaler Nephronabschnitte bei verschiedenen Diuresezuständen. Pfluegers Arch. Gesamte Physiol. Menschen Tiere. 280: 99. 